\title{
BMJ Open Development of unmanned aerial vehicle (UAV) networks delivering early defibrillation for out-of-hospital cardiac arrests (OHCA) in areas lacking timely access to emergency medical services (EMS) in Germany: a comparative economic study
}

\author{
Jan Bauer (D , , ${ }^{1}$ Dieter Moormann, ${ }^{2}$ Reinhard Strametz, ${ }^{3}$ David A Groneberg ${ }^{4}$
}

To cite: Bauer J, Moormann D, Strametz R, et al. Development of unmanned aerial vehicle (UAV) networks delivering early defibrillation for outof-hospital cardiac arrests (OHCA) in areas lacking timely access to emergency medical services (EMS) in Germany: a comparative economic study. BMJ Open 2021;11:e043791. doi:10.1136/ bmjopen-2020-043791

- Prepublication history for this paper is available online. To view these files, please visit the journal online (http://dx.doi. org/10.1136/bmjopen-2020043791).

Received 13 August 2020 Revised 30 December 2020 Accepted 12 January 2021

Check for updates

(c) Author(s) (or their employer(s)) 2021. Re-use permitted under CC BY-NC. No commercial re-use. See rights and permissions. Published by BMJ.

For numbered affiliations see end of article.

Correspondence to

Dr Jan Bauer;

j.bauer@med.uni-frankfurt.de

\section{ABSTRACT}

Objectives This study wants to assess the cost-effectiveness of unmanned aerial vehicles (UAV) equipped with automated external defibrillators (AED) in out-of-hospital cardiac arrests (OHCA). Especially in rural areas with longer response times of emergency medical services (EMS) early lay defibrillation could lead to a significant higher survival in OHCA.

Participants 3296 emergency medical stations in Germany.

Setting Rural areas in Germany.

Primary and secondary outcome measures Three UAV networks providing $80 \%, 90 \%$ or $100 \%$ coverage for rural areas lacking timely access to EMS (ie, time-to-defibrillation: $>10 \mathrm{~min}$ ) were developed using a location allocation analysis. For each UAV network, primary outcome was the costeffectiveness using the incremental cost-effectiveness ratio (ICER) calculated by the ratio of financial costs to additional life years gained compared with current EMS.

Results Current EMS with 3926 emergency stations was able to gain 1224 life years on annual average in the study area. The UAV network providing 100\% coverage consisted of 1933 UAV with average annual costs of $€ 43.5$ million and 1845 additional life years gained on annual average (ICER: €23568). The UAV network providing 90\% coverage consisted of 1074 UAV with average annual costs of $€ 24.2$ million and 1661 additional life years gained on annual average (ICER: €14548). The UAV network providing 80\% coverage consisted of 798 UAV with average annual costs of $€ 18.0$ million and 1477 additional life years gained on annual average (ICER: €12158). Conclusion These results reveal the relevant life-saving potential of all modelled UAV networks. Furthermore, all analysed UAV networks could be deemed cost-effective. However, real-life applications are needed to validate the findings.

\section{BACKGROUND}

The incidence of out-of-hospital cardiac arrests (OHCA) in Germany in 2018 was 121 per 100000 citizens with a survival to discharge rate of $13.2 \%$, based on
Strengths and limitations of this study

- This is the first large-scale analysis showing the cost-effectiveness of unmanned aerial vehicle (UAV) equipped with automated external defibrillators in out-of-hospital cardiac arrests compared with emergency medical services on national level.

- Depending on UAV coverage, cost-effectiveness was examined on national level accounting for existing emergency medical services, purchase prize, maintenance, UAV life span and life years gained.

- However, there are still technical, legal and practical issues to be resolved before the actual field implementation.

representative data taken from 31 emergency medical services (EMS). ${ }^{1}$ If cardiopulmonary resuscitation (CPR) is applied before the arrival of EMS, the 30-day survival rate is twice as high compared with no CPR before EMS arrival. ${ }^{2}$ EMS in Germany are represented by ambulance vehicles and/or emergency physician vehicles. In Germany, during $44.6 \%$ of OHCA settings, CPR was initiated by bystanders before the arrival of EMS. Furthermore, $22.4 \%$ of OHCA in Germany in 2018 showed a shockable rhythm in the initial rhythm analysis (ie, ventricular tachycardia or ventricular fibrillation). ${ }^{1}$ Since early defibrillation within the first $10 \mathrm{~min}$ after OHCA onset is a major aspect of CPR in OHCA, shorter time-to-defibrillation translates into higher survival rates. ${ }^{3}$ Time-to-defibrillation is defined as the interval from emergency call to first defibrillation. Defibrillation initiated $>10$ min after the emergency call has been placed, has a survival to discharge rate of 
$13.2 \%$, whereas patients who were defibrillated in $<2 \mathrm{~min}$ had a survival to discharge rate of $59.1 \% .{ }^{4}$ Similar conclusions were reported for Germany. ${ }^{56}$ Like many other countries, Germany has a nationwide network of EMS, which is based on specific predefined response times. However, especially in more rural areas, these response times often do not fall within the crucial first 10 min after the sudden onset of OHCA. In Germany, the mean time from emergency call to arrival at the scene of EMS was $6 \mathrm{~min}$ and $54 \mathrm{~s}$ in 2018. ${ }^{1}$ However, the mean time from emergency call to first defibrillation was $18.4 \mathrm{~min}$ (ie, only $20.7 \%$ of cases adhered to the proposed 8 min timeto-defibrillation). The large mean time gap between arrival at the scene and first defibrillation in 2018 may be due to difficulties reaching the patient, documentation error or few outliers. Bearing in mind that every minute defibrillation is delayed, fatal consequences for patients follow, efforts have been made to reduce the time-todefibrillation. This effort, however, is often hindered by costs (both regarding work force and infrastructure) and simple geography. Networks of publicly accessible AED have been established to improve the defibrillation rate. However, low accessibility leads to low utilisation ratios. ${ }^{78}$ Especially since the majority of OHCA happen at home (61.8\% in 2018 in Germany) and not in public places where most AED have been placed. ${ }^{1}$

These obstacles regarding accessibility of AED could be solved by the delivery of AED via an UAV or commonly known as 'drone'. The technical developments within the last decades have made UAV commercially available and their use have been expanded from their initial military use to humanitarian applications. ${ }^{9}{ }^{10}$ This study focused on UAV used to transport AED in OHCA cases. The feasibility of this concept has already been shown on a small scale. ${ }^{11}$ However, a large-scale analysis has not been conducted so far. In this study. we will focus on rural areas, since the potential benefit of UAV in rural areas was deemed to be higher compared with urban areas, where the availability and accessibility of EMS is higher with better outcomes in OHCA settings. ${ }^{12}$

The study wants to (1) develop UAV networks for rural areas providing a maximum time-to-defibrillation of 10 min and (2) evaluate different UAV-network configurations by cost-effectiveness compared with current EMS.

\section{METHODS}

The simulation of a UAV network was carried out for the entire territory of the Federal Republic of Germany fulfilling the following inclusion criteria: (1) area classified as 'thinly populated area' according to the degree of urbanisation (DEGURBA) as of 2018 defined by EUROSTAT based on the share of local population living in urban clusters and in urban centres ${ }^{13}$ and (2) not covered by EMS within 10 min time-to-defibrillation. These inclusion criteria defined an area that would most likely benefit from an UAV network. We retrieved all EMS locations (address) in Germany as of 2019 from the respective counties in Germany, where fully equipped ambulance vehicles (ie, DIN EN 1789 Typ C) and/or emergency physician vehicles were provided. All counties were contacted two times via email from December 2019 until March 2020. Missing data were retrieved manually by an exhaustive internet search from various sources. For EMS, the following time intervals were used (rounded to minutes):

1. Dispatch time between emergency phone call arrival and dispatch: 1 min. ${ }^{14}$

2. Driving time: depending on location of OHCA.

3. Time between arrival at scene and arrival at patient side: 3 min. $^{14}$

4. Time between arrival at patient side and first defibrillation: 1 min. ${ }^{15}$

Based on these time intervals, the driving time had to be $<5 \mathrm{~min}$ in order to provide the $10 \mathrm{~min}$ time-todefibrillation. In order to increase the discriminative power, we used a 7 min driving time $(5+2)$ for the calculation of service areas for EMS. The service areas were computed by a network analysis without restrictions but with increased speed limits (20\%) based on a road network of Germany provided by TomTom Multinet data (TomTom, Amsterdam, The Netherlands) as of 2016. All areas that were covered by EMS within 10 min timeto-defibrillation were excluded. The included study area was divided into grid cells with a resolution of $1 \mathrm{~km}^{2}$, excluding non-accessible and unincorporated areas (eg, forests, water bodies or mountain ranges).

\section{Spatial demand}

For the analysis, spatial demand was defined as the regional number of OHCA with shockable rhythm. The regional number of OHCA with shockable rhythm was derived from national data regarding OHCA cases as of 2018. These data were projected on municipality level and adjusted by gender (male/female) and age $(<18$ years, 18-80 years, $>80$ years) according to the respective proportion in OHCA cases (ie, in municipalities with an older population, a higher OHCA incidence was estimated). ${ }^{116}$ The projected regional number of OHCA falling within the study area was then evenly distributed among the grid cells within the municipality. Since grid cells representing non-accessible and unincorporated areas were excluded, the remaining grid cells were clustered in residential areas within a municipality leading to higher OHCA incidence in those areas compared with non-residential areas. This approach is in line with disaggregation methodology applied by the European Statistical Office. ${ }^{17}$ The disaggregation methodology is used to produce grids in the absence of geocoded microdata.

\section{UAV network}

Three UAV networks were developed to cover $80 \%, 90 \%$ and $100 \%$ of the demand in the study area. These percentages were chosen to guarantee equal access to defibrillation within the study area even if such coverages may not be the primary goal by a health policy addressing this 
issue. However, if UAV are deemed to be cost-effective, such coverages are likely to be the goal on the long run, to provide equal access within an area. The demand was covered if the time-to-defibrillation was $<10 \mathrm{~min}$. The following time intervals were used (rounded to minutes) ${ }^{1418}$ :

1. Dispatch time between emergency phone call and dispatch: $1 \mathrm{~min}$.

2. UAV flying time between take off and arrival at the scene: depending on location of OHCA.

3. Time between arrival at scene, retrieving AED and delivery to patient side: 2 min.

4. Time between arrival at patient side and first defibrillation: $2 \mathrm{~min}$.

The mentioned time intervals were approximates based on current literature assuming a dual bystander situation. ${ }^{19}$ The delivery of the AED by the UAV is assumed to be made by drop-off. In order to provide a maximum time-to-defibrillation of $10 \mathrm{~min}$, the maximum UAV flight time had to be $5 \mathrm{~min}$ (representing a radius of $8.33 \mathrm{~km}$ with $100 \mathrm{~km} /$ hour ground speed). Regarding possible UAV specifications, a distinction must be made between multirotor and tiltwing or tiltrotor systems. The former are less expensive (about $€ 30000$ ), but usually slower (about $50 \mathrm{~km} /$ hour), whereas tiltwing systems are more expensive (about $€ 50000$ ) but faster (about $100 \mathrm{~km} /$ hour).

To identify the minimum number of UAV base location providing universal coverage $(100 \%)$, a locationallocation solver was applied using the problem type 'minimum facilities' within ArcGIS Pro 2.5 (ESRI, Redlands, USA). The location-allocation solver uses Hillsman editing to generate a set of semi-randomised solutions. Then a vertex substitution heuristic is applied to refine the solutions. Finally, the solutions are combined by a metaheuristic to return near-optimal results. ${ }^{20}$ In order to identify the minimum number of UAV base locations covering $80 \%$ and $90 \%$ of the demand, we applied an iterative approach: first, we identified the UAV base location covering the maximum demand within a catchment of $8.33 \mathrm{~km}$. Second, this location and its covered demand were removed. With the remaining demand locations both steps were repeated. Using this approach, we were able to estimate the minimum number of base locations needed to cover $80 \%$ and $90 \%$ of the demand.

\section{Cost-effectiveness}

To simulate financial costs of UAV networks, the following assumptions were made: (1) UAV purchase prize (inlcuding AED): $€ 50000$, (2) annual UAV maintenance cost: $20 \%$ of purchase prize and (3) UAV lifespan: 4 years. ${ }^{18}$ The mean life expectancy of OHCA survivor was assumed to be 12 years as shown in a recent study. ${ }^{21}$ Survival to discharge in relation to time-to-defibrillation was modelled as follows: time-to-defibrillation 5-10 min: $33.1 \%$ survival; time-to-defibrillation $>10$ min: $13.2 \%$ survival. ${ }^{42}$ The incremental cost-effectiveness ratio (ICER) as the assessment of cost-effectiveness was calculated by the ratio of financial costs to the sum of the additional life years gained by UAV compared with EMS. The reference period for the calculation was the first 12 years (mean life expectancy of OHCA survivor). ${ }^{21}$

\section{Patient and public involvement}

Patients or the public were not involved in the design, or conduct, or reporting, or dissemination plans of our research.

\section{RESULTS}

We received data regarding EMS from 329 counties $(82.0 \%$ of all counties). All missing data could be retrieved manually. In 2019, there were 3296 EMS locations in Germany with a total of 4482 fully equipped ambulance vehicles and 1365 emergency physician vehicles excluding spare vehicles providing routine care. After applying all mentioned exclusion criteria, the remaining study area covered an area of $127936 \mathrm{~km}^{2}$ and a population size of 5261777 . In figure 1, the UAV network configuration for universal coverage (100\%) with adjoining EMS locations is shown for an exemplary region in southern Germany. The modelled demand (OHCA cases with shockable rhythm) in Germany in 2018 was 22 493. The modelled demand in the study area was 1427 cases (6.3\% of total cases).

The benchmark analysis (no UAV network in place) revealed that in the study area, where EMS time-todefibrillation was $>10 \mathrm{~min}$, a total of 14689 life years were gained in 12 years with an annual average of 1224 .

Compared with this benchmark the different UAV network configurations performed as follows (see also table 1): in order to provide universal coverage (100\%), the analysis revealed that $1933 \mathrm{UAV}$ were necessary. These translated into costs of $€ 512.9$ million in 12 years. In other words, the average annual costs were $€ 43.5$ million. However, in 12 years the UAV network was able to gain 22145 additional life years with an annual average of 1845 compared with the benchmark. The ICER for this UAV network configuration was $€ 23568$ per additional life year.

In order to cover $90 \%$ of the demand, 1074 UAV were necessary. This UAV network would cost $€ 24.2$ million per year and 19932 additional life years could be gained in 12 years with costs of $€ 14548$ per additional life year (ICER).

On the other hand, if only $80 \%$ of the demand was covered, the UAV network configuration resulted in the following configuration: 798 UAV were necessery, which translated into average annual costs of $€ 18.0$ million. By using this network, 17722 additional life years were gained in 12 years with an ICER of $€ 12158$ per additional life year.

\section{DISCUSSION}

We modelled three different UAV networks for rural areas providing a maximum time-to-defibrillation of $10 \mathrm{~min}$ 


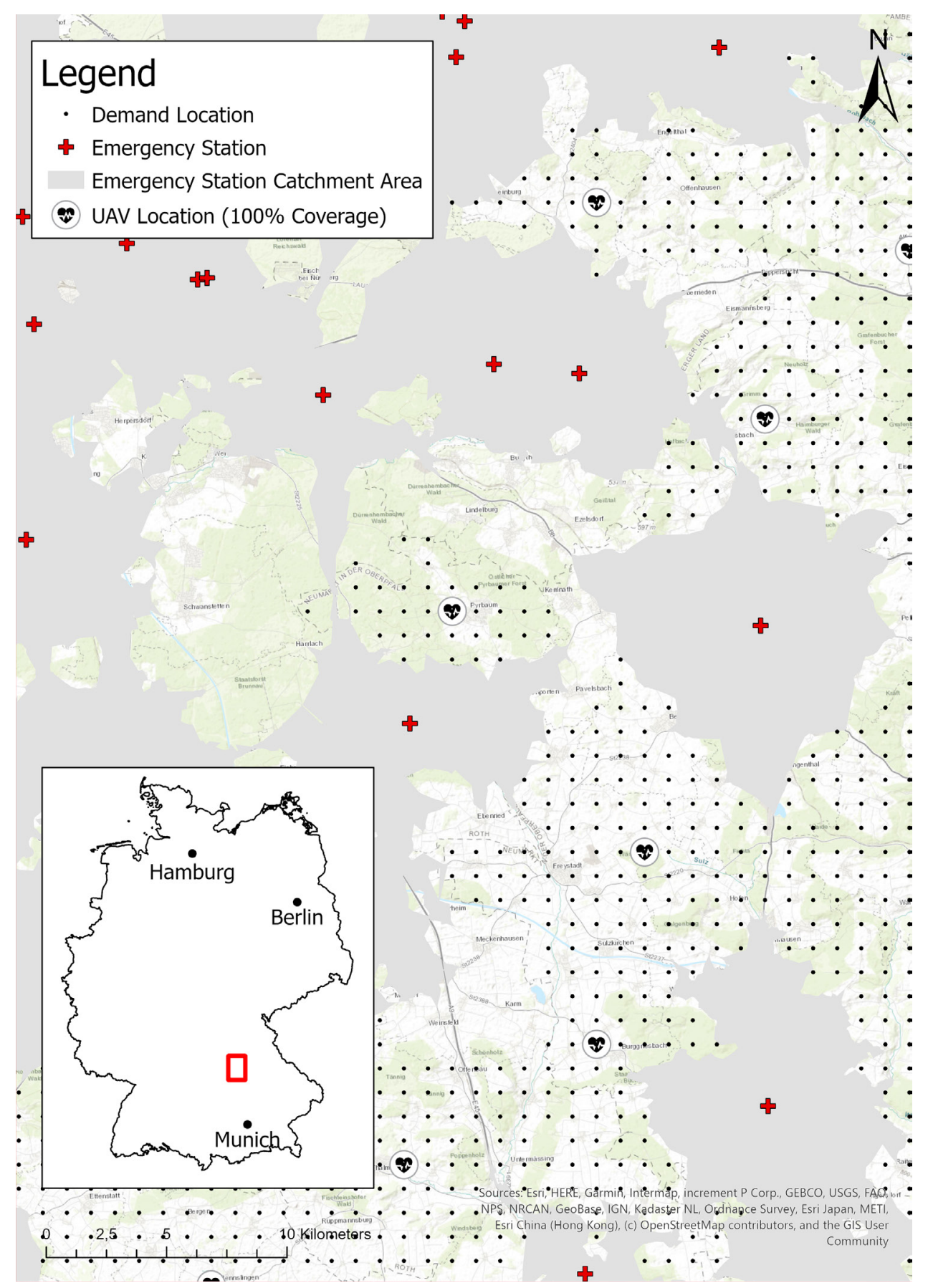

Figure 1 Unmanned aerial vehicle (UAV) network configuration for universal coverage (100\%) with adjoining emergency stations in an exemplary region in southern Germany.

Table 1 Overview of cost-effectiveness analysis using life years for different UAV network configurations

\begin{tabular}{|c|c|c|c|c|c|c|c|c|c|}
\hline \multicolumn{2}{|c|}{ UAV network } & \multicolumn{4}{|c|}{ Cost (million $€$ ) } & \multicolumn{3}{|c|}{ Additional life years ${ }^{* *}$} & \multirow[b]{2}{*}{$\operatorname{ICER}(€)$} \\
\hline Coverage & UAV (n) & Purchase* & $\begin{array}{l}\text { Maintenance } \\
\text { per year }\end{array}$ & $\begin{array}{l}\text { Total in } 12 \\
\text { years }\end{array}$ & $\begin{array}{l}\text { Annual } \\
\text { average }\end{array}$ & First year & $\begin{array}{l}\text { Total in } 12 \\
\text { years }\end{array}$ & $\begin{array}{l}\text { Annual } \\
\text { average }\end{array}$ & \\
\hline $90 \%$ & 1074 & 53.7 & 10.7 & 290.0 & 24.2 & 256 & 19932 & 1661 & 14548 \\
\hline $80 \%$ & 798 & 39.9 & 8.0 & 215.5 & 18.0 & 227 & 17722 & 1477 & 12158 \\
\hline
\end{tabular}

*Every 4 years due to UAV lifetime.

†Additional life years compared with the benchmark (ie, no UAV network).

ICER, incremental cost-effectiveness ratio; UAV, unmanned aerial vehicle. 
in Germany and evaluated their cost-effectiveness. Our results revealed the life-saving potential for all modelled UAV networks: providing universal coverage, the UAV network was able to gain 1845 additional life years on annual average. Even if the coverage was lowered to $80 \%$, the UAV network was still able to gain 1477 additional life years on annual average. The benefit in this cost-effective analysis (ICER) was operationalised by life years gained. However, the quality-adjusted life years (QALY) are often used instead. QALY are calculated by combining the lifetime gained by an intervention with the health-related quality of life. ${ }^{182324} \mathrm{~A}$ recent study showed that UAV networks can potentially gain 30267 additional QALY within 4 years. ${ }^{18}$ However, the concept of QALY is controversial, not least because of ethical questions being raised, which is why the unadjusted life years were used in the present study.

It must be noted that we assumed evenly distributed incidence of OHCA among the grid cells within a municipality. This leads to possible overestimation of UAV coverage since, in reality, the incidence of OHCA is unevenly distributed within a municipality or even within the grid cells. This bias was introduced due to a lack of data providing the exact location of historical OHCA in a municipality.

The National Institute for Health and Care Excellence in the UK stated that an intervention can be deemed cost-effective if the ICER is below $€ 22278$ ( $£ 20000)$ to $€ 33417$ (£30 000). ${ }^{25}$ Accordingly, the UAV networks with $80 \%$ and $90 \%$ coverage (ICER of $€ 12158$ and $€ 14548$, respectively) could be considered cost-effective. However, thresholds regarding cost-effectiveness are difficult to determine and therefore different thresholds have been applied internationally (eg, \$A46400 in Australia). ${ }^{26}$ The finding of cost-effectiveness was also reported in a study in North Carolina with an ICER of $€ 768$ (US\$858). ${ }^{18}$ However, due to the different underlying assumptions, this study is not directly comparable and the lower ICER can be explained by the inclusion of urban areas and a significantly lower estimated purchase prize $(€ 15000$ per UAV). In our study, we excluded urban areas since provision of EMS was assumed to be adequate and timely in urban areas. This is supported by Claesson $e t$ al, who reported a potential reduction of time-to-defibrillation in urban areas by $1.5 \mathrm{~min}$ and up to $19 \mathrm{~min}$ in rural areas compared with EMS. ${ }^{27}$ UAV networks have furthermore been studied in Toronto. Here, the analyses showed that 81 bases and 100 drones would be required to deliver an AED 3 min earlier compared with standard EMS. ${ }^{14}$ Thus, the presented results illustrate the possibilities that UAV represent for the survival of patients, especially in rural areas. It must be noted that the results were based on simulations and theoretical considerations and therefore uncertainties remain regarding financial costs and the life years gained. The financial costs were estimated under the assumption of large quantities, since the costs for prototypes are significantly higher. The estimates were also based on the assumption of a fully automated UAV network, which is monitored centrally translating in low personnel expenditure. However, due to technical progress, costs are expected to decrease in the future, so that the reported costs represent maximum costs and the ICER is likely to decrease in the future. For these reasons, the use of UAV networks in real OHCA situations must be evaluated. For such studies, our results could serve as a guide for the selection of potential study areas. Still, the concept of an AED equipped UAV has already been shown to be potentially feasible. ${ }^{11}$ The feasibility was furthermore shown in a study using an UAV in an out-ofsight flight to autonomously transport and deliver AED. ${ }^{28}$

In general, UAV within the medical scope have been mainly used within three categories: (1) medical transport (2) medical surveillance and observation and (3) disaster relief. ${ }^{9}{ }^{10}$ In regard to medical surveillance and observation, UAV have been used for the surveillance of swimmers in a Triathlon, ${ }^{29}$ simulated scenarios of drowning at the beach ${ }^{30}$ and on-site body documentation in crime scenes of forensic cases. ${ }^{31}$ Within these studies. UAV have been shown to provide better results compared with traditional approaches. Regarding disaster relief, UAV have been studied mainly in search and rescue operations. ${ }^{32-34}$ Here, a wider area could be searched faster by an UAV compared with the standard procedure. The same applied to the use of UAV within mass casualty incidents showing their feasibility. ${ }^{35} 36$ Lastly in regard to medical transport, UAV have been successfully used to transport laboratory samples, ${ }^{37}$ blood products, ${ }^{38} 39$ vaccines ${ }^{40}$ and flotation devices to prevent drowning. ${ }^{41}$ The use of AED equipped UAV can therefore be seen as a reasonable extension of the previous applications. ${ }^{28}$ However, so far, AED equipped UAV have not been implemented within common practice but are the focus of many national studies (eg, Sweden or Canada). ${ }^{28} 3342$ Theoretically, police officers and firefighters could be additionally dispatched instead of an UAV to reduce the time-todefibrillation in OHCA settings, where the response time of EMS would be too long. However, this is not standard care in Germany but happens occasionally if police or fire fighters have been dispatched for a different reason (eg, house fire or a possible crime). Including police and fire fighters within the rescue chain of a 'regular' OHCA would require specific regulations that address the legal, technical and personal aspects in Germany. In other countries such dual dispatch systems have already been studied or even implemented on regional level showing a moderate, but significant increase in the 30-day survival of OHCA cases. ${ }^{43}$ However, further studies are needed to address these issues more deeply.

The time-to-defibrillation threshold used in our study ( $10 \mathrm{~min})$ was chosen due to the significant decline of survival rates associated with delayed defibrillation exceeding $10 \mathrm{~min}$ after the emergency call. ${ }^{34}$ However, real-life application of AED-equipped UAV could heavily alter the time frames used in our study due to personal issues like aversion to UAV or handling insecurities. It must also be noticed that the time frames used have been 
adopted from international studies that may not reflect Germany-specific time frames. The principal acceptance of UAV for medical purposes has already been demonstrated in disaster scenarios. ${ }^{44}$ Also, it simulated OHCA settings, positive experiences have been reported interacting with an AED-equipped UAV ${ }^{45}$ In addition, it has been shown that the instructions given to first responder by the dispatchers are crucial to the success of using the AED correctly. ${ }^{19}$ Therefore, telephone instructions of resuscitation (T-CPR) are essential (T-CPR protocols). Furthermore, retrieving an AED in a single bystander OHCA situation would require an interruption of CPR: the median hands-off time in a simulation was reported to be $94 \mathrm{~s} .{ }^{19}$ Since continued CPR is the mainstay of any effort made by lay bystanders, CPR must be continued until a dual bystander situation develops where one bystander can proceed with CPR while the other one retrieves the AED. This issue, however, also applies to publicly accessible AED in a single bystander situation.

In our study, we assumed that every UAV base location is only equipped with a single UAV. Theoretically, this could reduce effectiveness if more than one OHCA occur at the same time within the UAV base locations catchment. Another study has shown that by using existing EMS locations to launch the UAV, $80.1 \%$ of the potential OHCA sites were reached within $1 \mathrm{~min}$ and adding new sites to launch UAV resulted in $90.3 \%$ of demand being reached. ${ }^{46}$ In our study, the potential UAV base locations were not identical to existing EMS locations. Using current EMS locations as UAV base locations would decrease the effectiveness in rural areas due to increasing UAV travel times.

Finally, it should be noted that the most frequent barriers regarding the application of UAV in the above-described scenarios were legal restrictions and technical problems. Such restrictions represent barriers regarding the implementation and the utilisation of UAV in such a setting: legal issues (eg, conflicts in airspace or no-fly zones) and technical issues (eg, weather conditions or maintenance) may prohibit or hinder the UAV utilisation. From a legal point of view, UAV must be provided an automatic launch license in case of an OHCA, otherwise obtaining a separate launch license would exceed both the relevant time frames and the costs. Therefore, a future implementation must be accompanied by both legal and technical aspects. Having said that, the results of this study demonstrate potential benefits of AED-equipped UAV in a best-case scenario with optimal circumstances.

\section{CONCLUSIONS}

The presented study demonstrated the relevant life-saving potential of UAV equipped with AED in out-of-hospital cardiovascular arrests: 1477 to 1845 additional years of life can be gained on an annual average compared with EMS. In relation, the financial costs UAV equipped with AED can be considered cost-effective. However, there are still technical, legal and practical issues to be resolved before the implementation in current practice.

\section{Author affiliations}

${ }^{1}$ Division of Health Services Research, Institute of Occupational Medicine, Social Medicine and Environmental Medicine, Goethe-Universitat Frankfurt am Main, Frankfurt, Germany

${ }^{2}$ Institute for Flight System Dynamics, RWTH Aachen University, Aachen, NordrheinWestfalen, Germany

${ }^{3}$ Wiesbaden Business School, RheinMain University of Applied Sciences, Wiesbaden, Hessen, Germany

${ }^{4}$ Institute of Occupational Medicine, Social Medicine and Environmental Medicine, Goethe-Universitat Frankfurt am Main, Frankfurt am Main, Hessen, Germany

Contributors JB designed the study, monitored data collection, cleaned and analysed the data, prepared cartographic material and drafted the paper. DM, RS and DAG revised the paper and contributed to methodological aspects of the study. All authors discussed and interpreted the results and contributed to the final manuscript.

Funding The authors have not declared a specific grant for this research from any funding agency in the public, commercial or not-for-profit sectors.

Map disclaimer The depiction of boundaries on this map does not imply the expression of any opinion whatsoever on the part of BMJ (or any member of its group) concerning the legal status of any country, territory, jurisdiction or area or of its authorities. This map is provided without any warranty of any kind, either express or implied.

Competing interests None declared.

Patient and public involvement Patients and/or the public were not involved in the design, or conduct, or reporting, or dissemination plans of this research.

Patient consent for publication Not required.

Provenance and peer review Not commissioned; externally peer reviewed.

Data availability statement Data are available on reasonable request.

Open access This is an open access article distributed in accordance with the Creative Commons Attribution Non Commercial (CC BY-NC 4.0) license, which permits others to distribute, remix, adapt, build upon this work non-commercially, and license their derivative works on different terms, provided the original work is properly cited, appropriate credit is given, any changes made indicated, and the use is non-commercial. See: http://creativecommons.org/licenses/by-nc/4.0/.

ORCID iD

Jan Bauer http://orcid.org/0000-0001-6267-9731

\section{REFERENCES}

1 Went J, Gräsner J, Seewald S. Öffentlicher jahresbericht ausserklinische reanimation, 2019.

2 Hasselqvist-Ax I, Riva G, Herlitz J, et al. Early cardiopulmonary resuscitation in out-of-hospital cardiac arrest. $N$ Engl $J$ Med 2015;372:2307-15.

3 Drennan IR, Lin S, Thorpe KE, et al. The effect of time to defibrillation and targeted temperature management on functional survival after out-of-hospital cardiac arrest. Resuscitation 2014;85:1623-8.

4 Hansen CM, Kragholm K, Granger CB, et al. The role of bystanders, first responders, and emergency medical service providers in timely defibrillation and related outcomes after out-of-hospital cardiac arrest: results from a statewide registry. Resuscitation 2015;96:303-9.

5 Nennecke A, Geiss K, Hentschel S, et al. Survival of cancer patients in urban and rural areas of Germany--a comparison. Cancer Epidemiol 2014;38:259-65.

6 Bürger A, Wnent J, Bohn A. The effect of ambulance response time on survival following out-of-hospital cardiac arrest-an analysis from the German resuscitation registry. Dtsch Arztebl Int 2018;115:541-8.

7 Agerskov M, Nielsen AM, Hansen CM, et al. Public access defibrillation: great benefit and potential but infrequently used. Resuscitation 2015;96:53-8.

8 Deakin CD, Anfield S, Hodgetts GA. Underutilisation of public access defibrillation is related to retrieval distance and time-dependent availability. Heart 2018;104:1339-43. 
9 Rosser JC, Vignesh V, Terwilliger BA, et al. Surgical and medical applications of Drones: a comprehensive review. JSLS 2018;22:e2018.00018.

10 Bhatt K, Pourmand A, Sikka N. Targeted applications of Unmanned aerial vehicles (Drones) in telemedicine. Telemed J E Health 2018;24:833-8.

11 Van de Voorde P, Gautama S, Momont A, et al. The drone ambulance [A-UAS]: golden bullet or just a blank? Resuscitation 2017;116:46-8.

12 Mathiesen WT, Bjørshol CA, Kvaløy JT, et al. Effects of modifiable prehospital factors on survival after out-of-hospital cardiac arrest in rural versus urban areas. Crit Care 2018;22:99.

13 Dijkstra L, Poelman H. A harmonised definition of cities and rural areas: the new degree of urbanisation. WP 01/2014. European Commission, 2014. http://ec.europa.eu/regional_policy/sources/ docgener/work/2014 01 new urban.pdf

14 Boutilier JJ, Brooks SC, Janmohamed A, et al. Optimizing a Drone network to deliver automated external defibrillators. Circulation 2017;135:2454-65.

15 Felder S, VanAarsen K, Davis M. Decreasing time to first shock: routine application of defibrillation pads in prehospital STEMI. CJEM 2020;22:82-5.

16 Datenschutzerklärung. Federal statistical office and statistical offices of the Länder. Municipality directory information system, 2019. Available: https://www.destatis.de/DE/ZahlenFakten/ LaenderRegionen/Regionales/Gemeindeverzeichnis/ Gemeindeverzeichnis.html [Accessed 5 Dec 2019].

17 Eurostat. Population grids, 2018. Available: https://ec.europa eu/eurostat/statistics-explained/index.php/Population grids\# Methodology [Accessed 17 Jun 2020].

18 Bogle BM, Rosamond WD, Snyder KT, et al. The case for Droneassisted emergency response to cardiac arrest. $N C$ Med $J$ 2019;80:204-12.

19 Sanfridsson J, Sparrevik J, Hollenberg J, et al. Drone delivery of an automated external defibrillator - a mixed method simulation study of bystander experience. Scand J Trauma Resusc Emerg Med 2019;27:40.

20 ESRI Inc. Algorithms used by the ArcGIS network analyst extension, 2020. Available: https://pro.arcgis.com/en/pro-app/latest/help/ analysis/networks/algorithms-used-by-network-analyst.htm [Accessed 17 Dec 2020].

21 Andrew E, Nehme Z, Wolfe R, et al. Long-Term survival following outof-hospital cardiac arrest. Heart 2017;103:1104-10.

22 Malta Hansen C, Kragholm K, Pearson DA, et al. Association of bystander and first-responder intervention with survival after out-of-hospital cardiac arrest in North Carolina, 2010-2013. JAMA 2015;314:255-64.

23 Sassi F. Calculating QALYs, comparing QALY and DALY calculations. Health Policy Plan 2006;21:402-8.

24 Whitehead SJ, Ali S. Health outcomes in economic evaluation: the QALY and utilities. Br Med Bull 2010;96:5-21.

25 Love-Koh J, Taylor M. Physical activity and the environment - final report, 2017.

26 Bertram MY, Lauer JA, De Joncheere K, et al. Cost-effectiveness thresholds: pros and cons. Bull World Health Organ 2016;94:925-30.

27 Claesson A, Fredman D, Svensson L, et al. Unmanned aerial vehicles (drones) in out-of-hospital-cardiac-arrest. Scand J Trauma Resusc Emerg Med 2016;24:1-9.

28 Claesson A, Bäckman A, Ringh M, et al. Time to delivery of an automated external defibrillator using a Drone for simulated out- of-hospital cardiac arrests vs emergency medical services. JAMA 2017;317:2332-4.

29 Homier V, de Champlain F, Nolan M, et al. Identification of swimmers in distress using Unmanned aerial vehicles: experience at the MontTremblant Ironman Triathlon. Prehosp Emerg Care 2020;24:1-8.

30 Claesson A, Svensson L, Nordberg P, et al. Drones may be used to save lives in out of hospital cardiac arrest due to drowning. Resuscitation 2017;114:152-6.

31 Urbanová P, Jurda M, Vojtíšek T, et al. Using drone-mounted cameras for on-site body documentation: 3D mapping and active survey. Forensic Sci Int 2017;281:52-62.

32 Lygouras E, Santavas N, Taitzoglou A, et al. Unsupervised human detection with an embedded vision system on a fully autonomous UAV for search and rescue operations. Sensors 2019;19:3542.

33 Clark DG, Ford JD, Tabish T. What role can unmanned aerial vehicles play in emergency response in the Arctic: a case study from Canada. PLoS One 2018;13:e0205299-16.

34 Karaca Y, Cicek M, Tatli O, et al. The potential use of unmanned aircraft systems (drones) in mountain search and rescue operations. Am J Emerg Med 2018;36:583-8.

35 Jain T, Sibley A, Stryhn H, et al. Comparison of unmanned aerial vehicle technology-assisted triage versus standard practice in triaging casualties by paramedic students in a mass-casualty incident scenario. Prehosp Disaster Med 2018;33:375-80.

36 Sibley AK, Jain TN, Butler M, et al. Remote scene Size-up using an Unmanned aerial vehicle in a simulated mass casualty incident. Prehosp Emerg Care 2019;23:332-9.

37 Ochieng WO, Ye T, Scheel C, et al. Uncrewed aircraft systems versus motorcycles to deliver laboratory samples in West Africa: a comparative economic study. Lancet Glob Health 2020;8:e143-51.

38 Amukele T, Ness PM, Tobian AAR, et al. Drone transportation of blood products. Transfusion 2017;57:582-8.

39 Wen T, Zhang Z, Wong KKL. Multi-objective algorithm for blood supply via unmanned aerial vehicles to the wounded in an emergency situation. PLoS One 2016;11:e0155176-22.

40 Haidari LA, Brown ST, Ferguson M, et al. The economic and operational value of using drones to transport vaccines. Vaccine 2016;34:4062-7.

41 Seguin $C$, Blaquière $\mathrm{G}$, Loundou $\mathrm{A}$, et al. Unmanned aerial vehicles (drones) to prevent drowning. Resuscitation 2018;127:63-7.

42 Mermiri MI, Mavrovounis GA, Pantazopoulos IN. Drones for automated external defibrillator delivery: where do we stand? $J$ Emerg Med 2020;59:660-7.

43 Hasselqvist-Ax I, Nordberg P, Herlitz J, et al. Dispatch of firefighters and police officers in out-of-hospital cardiac arrest: a nationwide prospective cohort trial using propensity score analysis. J Am Heart Assoc 2017;6. doi:10.1161/JAHA.117.005873. [Epub ahead of print: 04 Oct 2017].

44 Hart A, Chai PR, Griswold MK, et al. Acceptability and perceived utility of drone technology among emergency medical service responders and incident commanders for mass casualty incident management. Am J Disaster Med 2017;12:261-5.

45 Zègre-Hemsey JK, Grewe ME, Johnson AM, et al. Delivery of automated external defibrillators via Drones in simulated cardiac arrest: users' experiences and the Human-Drone interaction. Resuscitation 2020;157:83-8.

46 Pulver A, Wei R, Mann C. Locating AED enabled medical Drones to enhance cardiac arrest response times. Prehosp Emerg Care 2016;20:378-89. 